\title{
A low-molecular-weight angiogenic factor in cat retina
}

\author{
R. D. KISSUN, ${ }^{1}$ C. R. HILL, ${ }^{2}$ A. GARNER, ${ }^{1}$ P. PHILliPS,${ }^{3}$ \\ S. KUMAR, ${ }^{3}$ AND JACQUELINE B. WEISS ${ }^{2}$ \\ From the 'Department of Pathology, Institute of Ophthalmology, Cayton Street, London EC1V 9AT; \\ the ${ }^{2}$ Department of Rheumatology, University of Manchester Medical School, Manchester M13 9PT; \\ and the ${ }^{3}$ Clinical Research Laboratories, Christie Hospital and Holt Radium Institute, \\ Manchester M20 9BX
}

SUMMARY A low-molecular-weight angiogenic factor has been isolated from healthy adult cat retinas. The factor, which has been purified by diethylaminoethyl (DEAE) cellulose chromatography and affinity chromatography, stimulates neovascularisation of the chick chorioallantoic membrane and has a number of properties similar to those previously described for a tumour factor. The finding of an angiogenic factor in healthy retina and its relationship to previously described inhibitors of angiogenesis is discussed.

Retinal neovasularisation can be a serious complication in a number of ocular disorders. ${ }^{12}$ The observation that retinal capillary malperfusion often precedes neovascularisation ${ }^{3-5}$ and furthermore that destruction of the areas of nonperfused retina results in regression of the newly formed vessels ${ }^{67}$ has suggested that a diffusable substance with vasoproliferative properties may be formed by the ischaemic retina. Direct evidence for a retina-derived angiogenic factor has recently been reported. Federmann et al. ${ }^{8}$ observed the growth of limbal vessels toward implants of retinal tissue in rabbit corneas, and other workers $^{9-13}$ have demonstrated the presence of angiogenic activity in extracts of retinal tissue.

In this report we describe the purification of a factor from feline retina which in a crude form has been shown to stimulate growth of the limbal vessels into the rabbit cornea. ${ }^{9}$ Preliminary studies indicate that the factor has a low molecular weight and resembles a factor isolated from rat Walker 256 tumours ${ }^{1415}$ and from the synovial fluid of diseased joints. ${ }^{16}$

\section{Materials and methods}

Adult cats aged 4-6 years from the Institute of Ophthalmology colony were used in these studies. They were administered an overdose of pentobarbital (Sagatal), and the eyes were enucleated when the animals were under deep anaesthesia. The retinas

Correspondence to Dr J. B. Weiss. were removed immediately under sterile distillea water at $4^{\circ} \mathrm{C}$. Batches of 8 retinas were pooled and stored at $-40^{\circ} \mathrm{C}$.

The retinas ( 1 batch, 8 retinas) were thawed and homogenised for 1 minute at $4^{\circ} \mathrm{C}$ in a glass PotterElvehjem homogeniser. The homogenate was incubated at $4^{\circ} \mathrm{C}$ for 30 minutes and then spun at $600 \mathrm{~g}$ for 15 minutes at $4^{\circ} \mathrm{C}$. The supernatant was collected and the pellet re-extracted as described above. Both supernatants were pooled and spun at $100000 \mathrm{~g}$ for 1 hour at $4^{\circ} \mathrm{C}$, when the clear supernatant was decanted and purified by diethylaminoethyl (DEAE) cellulose column chromatography and by affinity chromatography using a modification of the method described for the purification of a tumour angiogenic factor. ${ }^{14}$

DEAE CELLULOSE CHROMATOGRAPHY

Solid ammonium bicarbonate was added to the $100000 \mathrm{~g}$ supernatant to give a final concentration of $50 \mathrm{mM}$ salt. This sample was applied to a column $(8 \times 1$ $\mathrm{cm}$ ) of DEAE cellulose (Whatman) equilibrated with $50 \mathrm{mM} \mathrm{NH}_{4} \mathrm{HCO}_{3}(\mathrm{pH} 7.9)$ at $4^{\circ} \mathrm{C}$. Unbound material was eluted with the same buffer at a flow rate of 50 $\mathrm{ml} / \mathrm{h}$. The column effluent was monitored at $280 \mathrm{~nm}$ (Uvicord S, LKB, Sweden) and $14 \mathrm{ml}$ fractions were collected. Bound material was eluted with a convex salt gradient $(0-0.3 \mathrm{M} \mathrm{NaCl})$ prepared in a constant level mixing device from $50 \mathrm{mM} \mathrm{NH} \mathrm{NCO}_{3}(65 \mathrm{ml})$ and $50 \mathrm{mM} \mathrm{NH}_{4} \mathrm{HCO}_{3}(100 \mathrm{ml})$ containing $0.3 \mathrm{M}$ $\mathrm{NaCl}$. The column was finally washed with $50 \mathrm{mM}$ $\mathrm{NH}_{4} \mathrm{HCO}_{3}$ containing $0 \cdot 5 \mathrm{M} \mathrm{NaCl}$. 


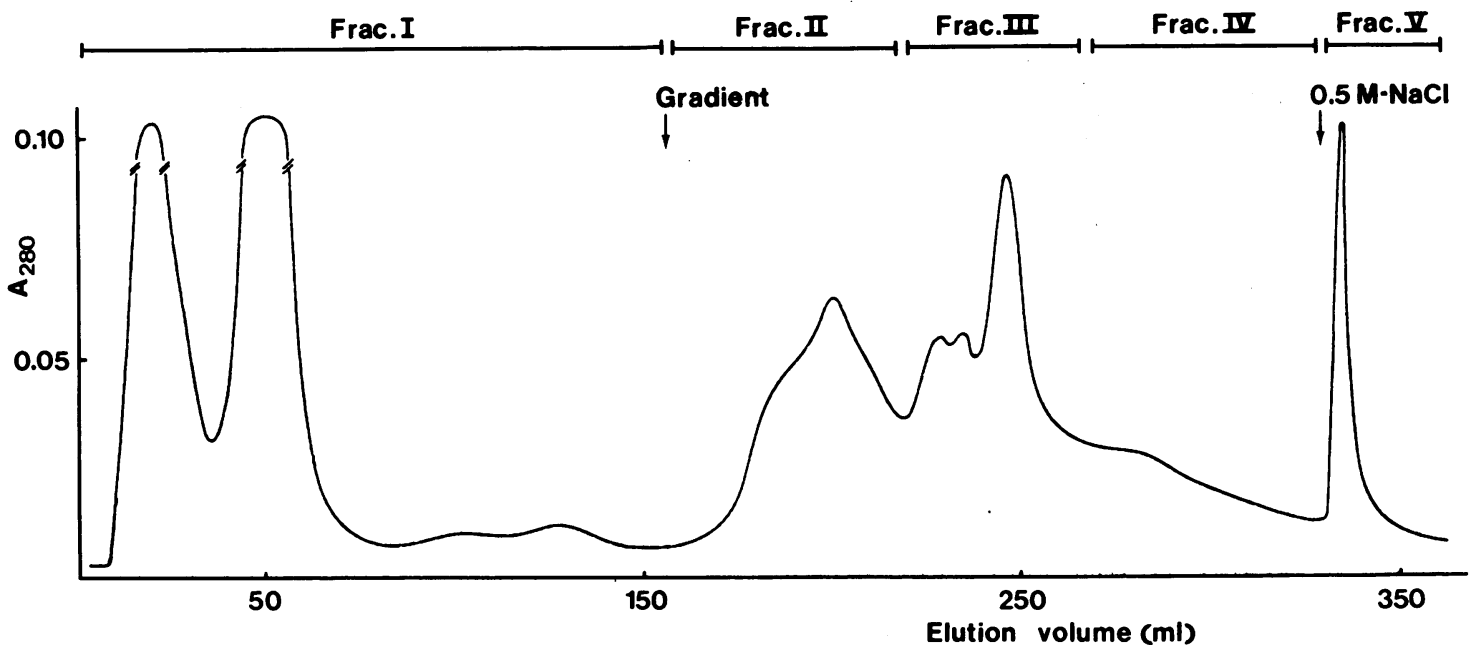

Fig. 1 DEAE cellulose chromatography of retinal homogenate.

\section{AFFINITY CHROMATOGRAPHY}

Fractions corresponding to regions I-V of the DEAE cellulose column elution profile (Fig. 1) were pooled and purified by affinity chromatography. An antibody prepared against tumour-derived angiogenic factor ${ }^{17}$ was bound to cyanogen bromide activated Sepharose 4B (Pharmacia, Uppsala, Sweden) (10 mg of IgG to 1 g dry Sepharose 4B), and a column of the affinity absorbent was prepared $(3 \times 1 \mathrm{~cm})$ and equilibrated with $50 \mathrm{mM} \mathrm{NH}_{4} \mathrm{HCO}_{3}$ containing $0.5 \mathrm{M} \mathrm{NaCl}$ at $4^{\circ} \mathrm{C}$. Fractions $\mathrm{I}-\mathrm{V}$ were pumped separately on to the affinity column $(30 \mathrm{ml} / \mathrm{h})$, and unbound material was eluted in each case with the same buffer. Specifically bound material was eluted with $50 \mathrm{mM}$ acetic acid adjusted to $\mathrm{pH} 3.5$ with 0.880 ammonia. The column effluent was monitored at $280 \mathrm{~nm}$, and $1 \mathrm{ml}$ fractions were collected.

Extracts of feline iris and rat liver were also prepared by the method described for the feline retina. In a further control experiment a sample of 50 $\mathrm{mM}$ ammonium bicarbonate buffer $(8 \mathrm{ml})$ was chromatographed on the DEAE cellulose and affinity columns.

Fractions were assayed for angiogenic activity by the chick chorioallantoic membrane (CAM) assay system previously described. ${ }^{14} 17$ Samples for assay

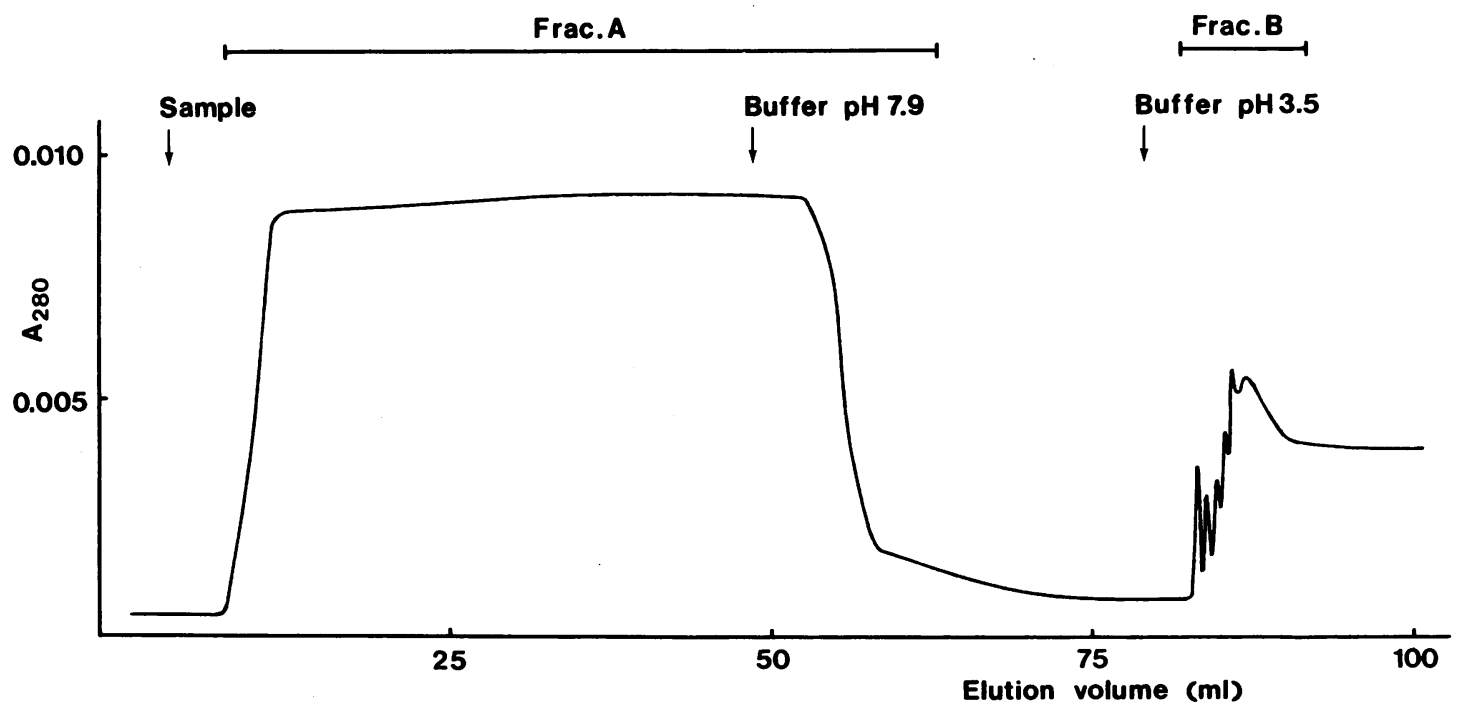

Fig. 2 Affinity chromatography of retinal extract. 

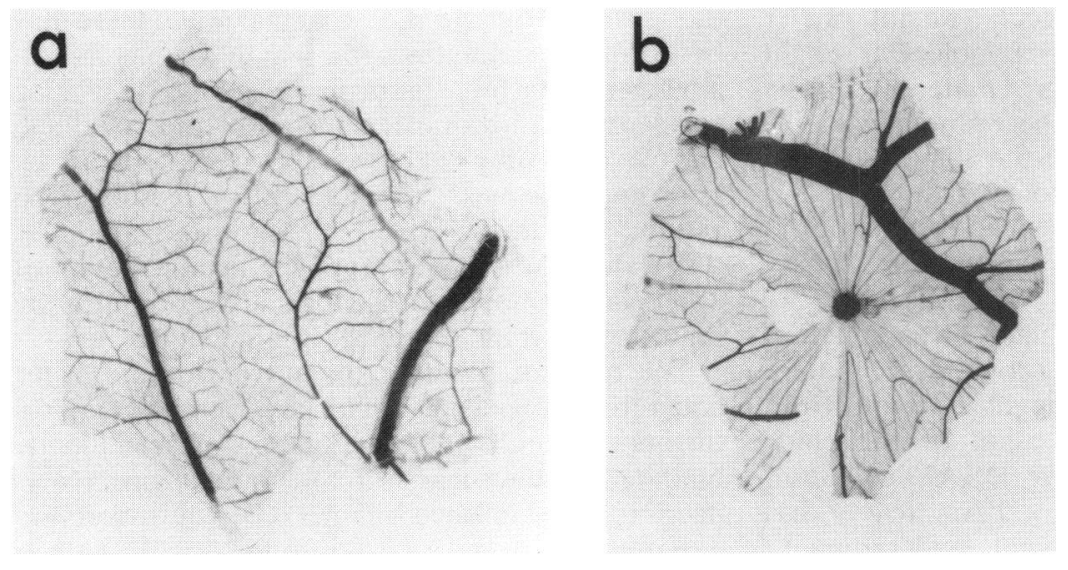

were sterilised by filtration through a $0.22 \mu \mathrm{m}$ membrane and freeze-dried before application to the CAM.

\section{Results}

A typical DEAE cellulose chromatography elution profile is shown in Fig. 1. Fraction I contained material unbound by the DEAE cellulose, fractions II-IV contained material eluted by a convex gradient of $0-0 \cdot 3 \mathrm{M} \mathrm{NaCl}$, and fraction $\mathrm{V}$ contained material eluted by a $0.5 \mathrm{M} \mathrm{NaCl}$ wash. Angiogenic activity was identified by the CAM assay technique and was detected in fractions IV and V. Material from the unbound peak (fraction 1) did not give a positive angiogenic response on the CAM.

Fractions I-V were further purified by affinity chromatography using Sepharose-bound antibody raised against a tumour-derived angiogenic factor. Unbound material was contained in fraction A (Fig. 2 ) and specifically bound material in fraction $B$. The majority of the $280 \mathrm{~nm}$ absorbing material was not bound to the affinity column. The small irregular peak corresponding to fraction B (Fig. 2) was caused by the mixing of the washing buffer $\mathrm{pH} 7.9$ and the eluting buffer $\mathrm{pH} 3.5$. The elevated base line after fraction $B$ was due to the absorbance of the $50 \mathrm{mM}$ ammonium acetate buffer. The presence of angiogenic factor in fraction $B$ could be detected only by the biological assay, as no detectable change attributable to the factor occurred in the recorder trace at $280 \mathrm{~nm}$.

Those fractions that were initially positive after chromatography on DEAE cellulose always gave a positive fraction B after affinity chromatography, whereas those fractions that were initially negative from DEAE cellulose chromatography did not give a positive fraction $B$. No fractions from DEAE chromatography of a buffer control and extracts of feline iris and rat liver prepared by the method described above induced neovascularisation of the CAM either before or after affinity chromatography.

A typical chorioallantoic membrane response to a sample of retina-derived angiogenic factor is shown in Fig. 3. The positive reaction in Fig. $3 \mathrm{~b}$ involves the bending in of medium sized vessels and the spokewheel appearance of small vessels growing towards the point of sample application. No such directional growth can be seen on the control membrane (Fig. 3a).

Active freeze-dried material from an affinity column was dissolved in $50 \mathrm{mM} \mathrm{NH}_{4} \mathrm{HCO}_{3}(5 \mathrm{ml})$ and dialysed against $50 \mathrm{mM} \mathrm{NH}_{4} \mathrm{HCO}_{3}(5 \mathrm{ml})$ at $4^{\circ} \mathrm{C}$ for 2 hours. After freeze drying the diffusate and retentate were both found to contain angiogenic activity when tested on the CAM, indicating that the active component was freely diffusible.

\section{Discussion}

A low-molecular-weight factor that stimulates neovascularisation of the chick CAM has been purified from the retinas of healthy adult cats. The factor resembles a low-molecular-weight tumour angiogenic factor previously described. ${ }^{14}$ Both factors are anionic as indicated by their binding to DEAE cellulose and are also eluted from the DEAE cellulose by a similar concentration of sodium chloride, indicating a comparable charge density. The retina angiogenic factor and the tumour factor give similar reactions on the chick chorioallantoic membrane and appear to be antigenically similar, as they both bind specifically to an antibody raised against the tumour factor. After purification by affinity chromatography both factors are dialysable. The crude tumour factor is nondialysable after chromatography on DEAE cellulose but becomes freely dialysable after affinity chromatography. It is presumed that the crude tumour factor 
is associated with a high-molecular-weight carrier molecule which gives it an apparent molecular weight far in excess of that for the purified material..$^{1418}$ The same appears to be true for the retina angiogenic factor. Again it is not until after the affinity chromatography step that the factor becomes dialysable. This suggests that the active component is separated from a carrier protein complex during the affinity procedure.

The feline retina angiogenic factor has a number of of properties similar to those described by D'Amore et $a .^{13}$ for bovine retina angiogenic factor. Both factors stimulate neovascularisation of the chick CAM and both are bound by DEAE cellulose. However, the factor described by D'Amore et al. has a relatively high molecular weight, and treatment with a number of dissociating reagents, including ethanol, used previously to purify a low-molecularweight angiogenic factor from tumours, failed to reduce the molecular weight of their active retinal material. The extraction procedure used in this work. homogenisation followed by incubation at $4^{\circ} \mathrm{C}$, may be a more effective preparative method than incubation alone as used by D'Amore et al. Possibly the bovine retinal factor exists solely as a high-molecularweight molecule. However, it may be that binding of the retinal factor by the antibody weakens the carrierangiogenic factor interaction more effectively and that this treatment has allowed the preparation of a lowmolecular-weight material. On the other hand Chen and Chen ${ }^{10}$ reported the isolation of an angiogenic factor which they described as 'a small molecule' from the retina of a number of mammalian species including bovine.

The findings in the present study indicate that angiogenic activity is present in healthy retina. A possible explanation for the absence of preretinal neovascularisation in the healthy state is that the vitreous, which is normally avascular, has been shown to contain substances that will inhibit the growth of new blood vessels. ${ }^{19-21}$ Such inhibitors may be involved in controlling the activity of any retinal angiogenic factor. This does not of course preclude the possibility that the retina itself contains inhibitors as well as activators of angiogenesis.

Henkind $^{2}$ has emphasised from careful clinical observations that retinal neovascularisation requires both an abnormal retinal vascular bed (diseased vessels) and an embarrassed (hypoxic) sensory retina. Furthermore he suggests that if perfusion is relatively normal the retinal vessels will not proliferate in spite of the presence of angiogenic substances.

The primary events therefore in the initiation of new blood vessel growth may not necessarily involve increased production of angiogenic factor(s). If both activator and inhibitor are present at equilibrium in the normal retina, in the ischaemic retina there may be a loss of inhibitor rather than an increase in angiogenic factor, particularly if the activating substance is a low-molecular-weight compound and therefore possibly not susceptible to degradation by lysosomal enzymes. Consequently it is reasonable to assume that this relative increase in activator may stimulate neovascularisation. The demonstration of appreciable amounts of angiogenic factor in healthy feline retina would support this contention.

The question whether tumour angiogenic factor and retinal angiogenic factor are identical requires further research, although their similar antibody binding affinities suggests a close resemblance. It also needs to be established whether different workers are describing the same or different factors. Both these questions should be answered when precise structural characterisation has been achieved.

This work was supported in part by grants from the Arthritis and Rheumatism Council and the British Diabetic Association.

\section{References}

1 Jampol LM. Goldbaum MH. Peripheral proliferative retinopathies. Surv Ophthalmol 1980: 25: 1-14.

2 Henkind P. Ocular neovascularisation. Am J Ophthalmol 1978: 85: 287-301.

3 Wise CN. Retinal neovascularisation. Trans Am Ophthalmol Soc 1956: 54: 729-826.

4 Ashton N. Retinal vascularisation in health and disease. Am J Ophthalmol 1957: 44: 7-17.

5 Goldberg MF. Classification and pathogenesis of proliferative sickle retinopathy. Am J Ophthalmol 1971: 71: 649-55.

6 Krill AE. Archer D. Newell FW. Photocoagulation in complications secondary to branch vein occlusion. Arch Ophthalmol 1971: 85: 48-60.

7 Kohner EM. Shilling JS. Hamilton AM. The role of avascular retina in new vessel formation. Metabol Ophthalmol 1976: 1: $15-23$.

8 Federmann JL. Brown GC. Feldberg NT. Felton SM. Experimental ocular angiogenesis. Am J Ophthalmol 1980: 89: 231-7.

9 Kissun RD. Garner A. Vasoproliferative properties of normal and hypoxic retinal tissues. Br J Ophthalmol 1977; 61: 394-8.

$10 \mathrm{Chen} \mathrm{CH}$. Chen SC. Angiogenic activity of vitreous and retinal extract. Invest Ophthalmol Visual Sci 1980; 19: 596-6)2.

11 Glaser BM. D'Amore PA. Michels RG, et al. The demonstration of angiogenic activity from ocular tissues. Preliminary report. Ophthalmologv 1980; 87: 440-6.

12 Glaser BM. D'Amore PA. Michels RG. Patz A. Fenselau A Demonstration of vasoproliferative activity from mammalian retina. J Cell Biol 1980; 84: 298-304.

13 D'Amore PA. Glaser BM. Brunson SK. Fenselau AH. Angiogenic activity from bovine retina. Partial purification and characterisation. Proc Natl Acad Sci USA 1981: 78: 3068-72.

14 Weiss JB. Brown RA. Kumar S. Phillips P. An angiogenic factor isolated from tumours: a potent low molecular weight compound. Br J Cancer 1979; 40: 493-6.

15 McAuslan BR. Hoffman H. Endothelial stimulating factor from Walker carcinoma cells. Relation to tumour angiogenic factor. Exp Cell Res 1979: 119: 181-90.

16 Brown RA. Weiss JB. Tomlinson IW. Phillips P. Kumar S Angiogenic factor from synovial fluid resembling that from tumours. Lancet 1980; i: 682-5. 
17 Phillips P. Kumar S. Tumour angiogenesis factor and its neutralisation by a xenogenic antiserum. Int J Cancer 1979; 23: 82-8.

18 Folkman J. Merler M. Abernathy C. Williams G. Isolation of a tumour factor responsible for angiogenesis. J Exp Med 1971: 33: 275-88.

19 Brem S. Brem H. Folkman J. Finkelstein D. Patz A. Prolonged tumor dormancy by prevention of neovascularisation in vitreous. Cancer Res 1976: 36: 2807-12.

20 Brem S. Preis I. Langer R. Brem H. Folkman J. Patz A. Inhibition of neovascularisation by an extract derived from vitreous. Am J Ophthalmol 1977; 84: 323-8.

21 Felton SM. Brown GC. Felberg NT. Federman JL. Vitreous inhibition of tumor neovascularisation. Arch Ophthalmol 1979; 97: 1710-3. 